\title{
ÍNDICES DE DENSIDADE E SOMBREAMENTO ARBÓREO EM ÁREAS VERDES PÚBLICAS DE ARACAJU, SERGIPE
}

\author{
Everaldo Marques de Lima Neto ${ }^{1}$, Rosemeri Melo e Souza. ${ }^{2}$
}

\begin{abstract}
RESUMO
O presente trabalho tem o objetivo de realizar um diagnóstico ambiental do complexo arbóreo urbano, usando índices espaciais para avaliar quantitativamente a arborização nas das áreas verdes públicas de Aracaju-SE. A metodologia consiste na identificação das espécies arbóreas presentes através de chaves taxionômicas e aplicação dos índices espaciais: de Sombreamento Arbóreo (ISA) e de Densidade Arbórea (IDA). No levantamento realizado identificou-se que as 5 (cinco) espécies que apresentaram maior freqüência foram Pithecellobium glaziovii (Mata-fome), Terminalia cattapa (Amendoeira), Licania tomentosa (Oiti), Clitoria fairchildiana (Sombreiro), Ficus spp. (Ficus), distribuídas em respectivas percentagens, $24,59 \%, 20,31 \%, 10,32 \%, 10,10 \%$ e 9,44\%. Os IDA's obtidos foram de 0,60 indivíduos arbóreos para cada $100 \mathrm{~m}^{2}$ na Zona Norte, e 0,61 no Centro e 0,68 na Zona Sul. Os ISA's da Zona Sul (68\%) e do Centro (62\%) indicam um maior potencial na capacidade de sombreamento arbóreo em relação a Zona Norte (39\%). Os resultados obtidos vêm demonstrar que o patrimônio arbóreo apresenta má distribuição do quantitativo de espécies denotando que as áreas verdes públicas não possuem políticas específicas de preservação, conservação e manutenção. De modo essencial faz-se necessário uma ação dos órgãos responsáveis pela arborização dos espaços públicos analisados na cidade.
\end{abstract}

Palavras-chave: arborização urbana, índices espaciais, áreas verdes, Aracaju(SE).

\section{DENSITY AND SHADE TREE INDEX IN PUBILC GREEN AREAS OF ARACAJU, SERGIPE, BRAZIL}

\begin{abstract}
ABSTRATCT
This work aims to achieve an environmental diagnosis of the complex urban trees, using spatial indexs to quantitatively evaluating arborization in the public green areas in AracajuSE. The methodology consists in identifying the tree species present in taxonomic keys and

\footnotetext{
1. Engenheiro Florestal - Mestrando em Engenharia Florestal/UFPR, Curitiba/PReveraldo.limaneto@gmail.com

2. Geógrafa, Profa. Associada do Departamento de Geografia/UFS, São Cristóvão/Sergipe rome@ufs.br
} 
application of spatial indices: Shading from trees (ISA) and tree density (IDA). In the survey identified that the five (5) species that showed higher frequencies were Pithecellobium glaziovii (Mata-fome), Terminalia cattapa (Amendoeira), Licania tomentosa (Oiti), Clitoria fairchildiana (Sombreiro), Ficus spp. (Ficus), distributed in their percentages, 24.59\%, $20.31 \%, 10.32 \%, 10.10 \%$ and $9.44 \%$. The IDA's were subjects of 0.60 trees for every $100 \mathrm{~m}^{2}$ in North Zone, Central Zone and 0.61 in and 0.68 in South Zone. The ISA's South Zone $(68 \%)$ and Central Zone (62\%) indicate a greater potential in the ability of shade trees on the North Zone (39\%). The results have shown that the heritage tree shows poor distribution of number of species showing that the public green areas do not have specific policies for the preservation, conservation and maintenance. In essence it is a necessary action of institutions responsible for arborization of public spaces in the city.

Key-Words: urban arbotization, spatial index, green areas, Aracaju(SE).

\section{INTRODUÇÃO}

A arborização é essencial a qualquer planejamento urbano e tem funções importantíssimas como: propiciar sombra, purificar o ar, atrair aves, diminuir a poluição sonora, constituir fator estético e paisagístico, diminuir o impacto das chuvas, contribuindo para o balanço hídrico, valorizar a qualidade de vida local. Portanto, as áreas verdes vêm assegurar a melhoria da cidade, no âmbito ecológico e paisagístico, disponibilizando recursos para melhorar a qualidade de vida urbana.

Nesse contexto, tem-se que a arborização presentes nas áreas verdes públicas é objeto de estudo para melhor funcionamento dessas áreas quanto suas funções resultando no aumento da qualidade de vida humana e ambiental dentro das cidades.

Os índices espaciais são definidos como um conjunto de parâmetros utilizados para estudo da arborização presentes nas áreas verdes, à medida que se realiza a mensuração destes, será obtida uma melhor ou pior condição da arborização, e de fato exercerá influência na qualidade áreas verdes.

A quantificação e a configuração espacial do "verde urbano" podem ser utilizadas como instrumentos e parâmetros de avaliação da qualidade ambiental em áreas urbanas (NUCCl; CAVALHEIRO, 1999; NUCCI, 2001).

A qualidade ambiental é um fator imprescindível no bem estar da sociedade, assim Lombardo (1985, p.16) afirma que a qualidade da vida humana está diretamente relacionada com a interferência da obra do homem no meio natural urbano. A natureza humanizada, através das modificações no ambiente alcança maior expressão nos espaços ocupados pelas cidades, criando um ambiente artificial. 
Jesus (2006, p. 53) ressalta que "a ausência de uma adequada área verde, tanto influi negativamente na qualidade ambiental, quanto na saúde da população." A avaliação da cobertura de árvores na cidade pode ajudar no planejamento da vegetação urbana e na sua administração, na medida em que revela características da vegetação, determina a extensão e a distribuição da vegetação.

A partir daí, os índices espaciais de sombreamento e densidade arbórea trazem consigo uma relevante contribuição para estudos de planejamento urbano, qualidade ambiental e arcabouço de modificação da paisagem nas áreas verdes públicas.

Partindo deste pressuposto, o Índice de Sombreamento Arbóreo é um procedimento metodológico em que o percentual da área sombreada em relação à área total, ambas relativas às áreas verdes. Onde o resultado obtido é o potencial de sombra resultante da soma das áreas de copa arbórea, que, por sua vez é estimada por meio de projeção visual ao solo, aproximada pela composição de polígonos. A área de sombreamento arbóreo utilizado parte da premissa de que em algum momento do dia a área de copa vai se projetar sobre a área da praça, proporcionando melhor conforto térmico além de menor poluição visual e sonora.

Macedo (2005, p. 324-326) ao estudar os impactos ambientais na Região Metropolitana de São Paulo, afirma que "a poluição sonora é considerada como um dos principais problemas em ambientes urbanos" que "causa ou agrava problemas de saúde relacionada ao estresse, tais como hipertensão, distúrbios psicológicos e do sono". Desse modo, é fundamental a presença das áreas verdes urbanas para atenuar os ruídos urbanos, viabilizando o conforto acústico aos moradores.

Sendo assim o IDA - Índice de Densidade Arbórea tem um papel importante por ser utilizado para verificar a intensidade de ocupação das árvores em determinada área verde, denotando maior ou menor quantidade no ambiente analisado.

A falta de planejamento técnico, de acompanhamento de um plantio adequado às diversas situações. No acompanhamento de condução, de podas erradas e mesmo de laudos técnicos incorretos, das condições fitossanitárias do vegetal, até a falta de condições de trabalho adequadas ao exercício da profissão, são causas que muitas vezes colocam árvores urbanas como um estorvo na cidade. E assim, a extirpação pura e simples vem sendo utilizada como "remédio" para a solução dos problemas (BATISTA, 2002).

A avaliação da cobertura vegetal permite não só conhecer dos índices relativos à quantidade de áreas verdes sombreadas ou densidade arbórea, bem como identificar, caracterizar e quantificar o patrimônio das espécies arbóreas existentes nas cidades.

É importante buscar alternativas que indiquem oportunidades de promoção de plantio, manutenção e conservação de espécies que harmonizem com o conjunto de equipamentos sociais urbanos, implicando assim na eliminação de conflitos existentes e na 
preservação e aumento da massa arbórea nas cidades, contribuindo efetivamente para a melhoria do ambiente nos centros urbanos (BATISTA, 2002).

O presente trabalho tem o objetivo de realizar um diagnóstico ambiental do complexo arbóreo urbano, por meio de índices espaciais determinando condições das áreas verdes públicas e avaliando quantitativamente a arborização nas praças da cidade de Aracaju-SE, visando planejamento, conservação e manutenção da arborização nas áreas verdes urbanas.

\section{MATERIAL E MÉTODOS}

\section{Localização e caracterização geográfica da área de estudo}

“O município de Aracaju está localizado entre as coordenadas geográficas 1054'40" latitude sul, 3704'18" longitude oeste de Greenwintch, e 4,9 metros de altitude. No que diz respeito ao clima, apresenta precipitação média anual de $1.590 \mathrm{~mm}$, temperatura média

anual entre 25 e $26^{\circ} \mathrm{C}$, com período chuvoso de março a agosto. O tipo é megatérmico úmido e subúmido com moderada deficiência no verão (ARAújo et al, 2006), o que denota maior necessidade de arborização na cidade pelos múltiplos benéficos ao clima urbano.

Segundo o censo de 2007 do IBGE, Aracaju possui uma população de 503.092 habitantes, com uma densidade demográfica de 2.891,33 hab/ $\mathrm{km}^{2}$. O Município de Aracaju limita-se em sua porção Norte, com o Rio do Sal, separando do Município de Nossa Senhora do Socorro, e na porção Sul, limita-se com o Rio Vaza Barris. A Oeste, com os municípios de São Cristóvão e Nossa Senhora do Socorro, e a Leste, com o Rio Sergipe e o Oceano Atlântico.

A área de estudo foi dividida em três porções (Figura 01), sendo elas: Zona Norte, Centro e Zona Sul. A Zona de Expansão, que é um prolongamento da Zona Sul, não foi incluída na área de pesquisa devido a sua malha urbana ser incompleta, ainda sem delimitação em bairros, onde a ocupação e transformação do solo pela ação antropogênica está em processo de configuração espacial. 


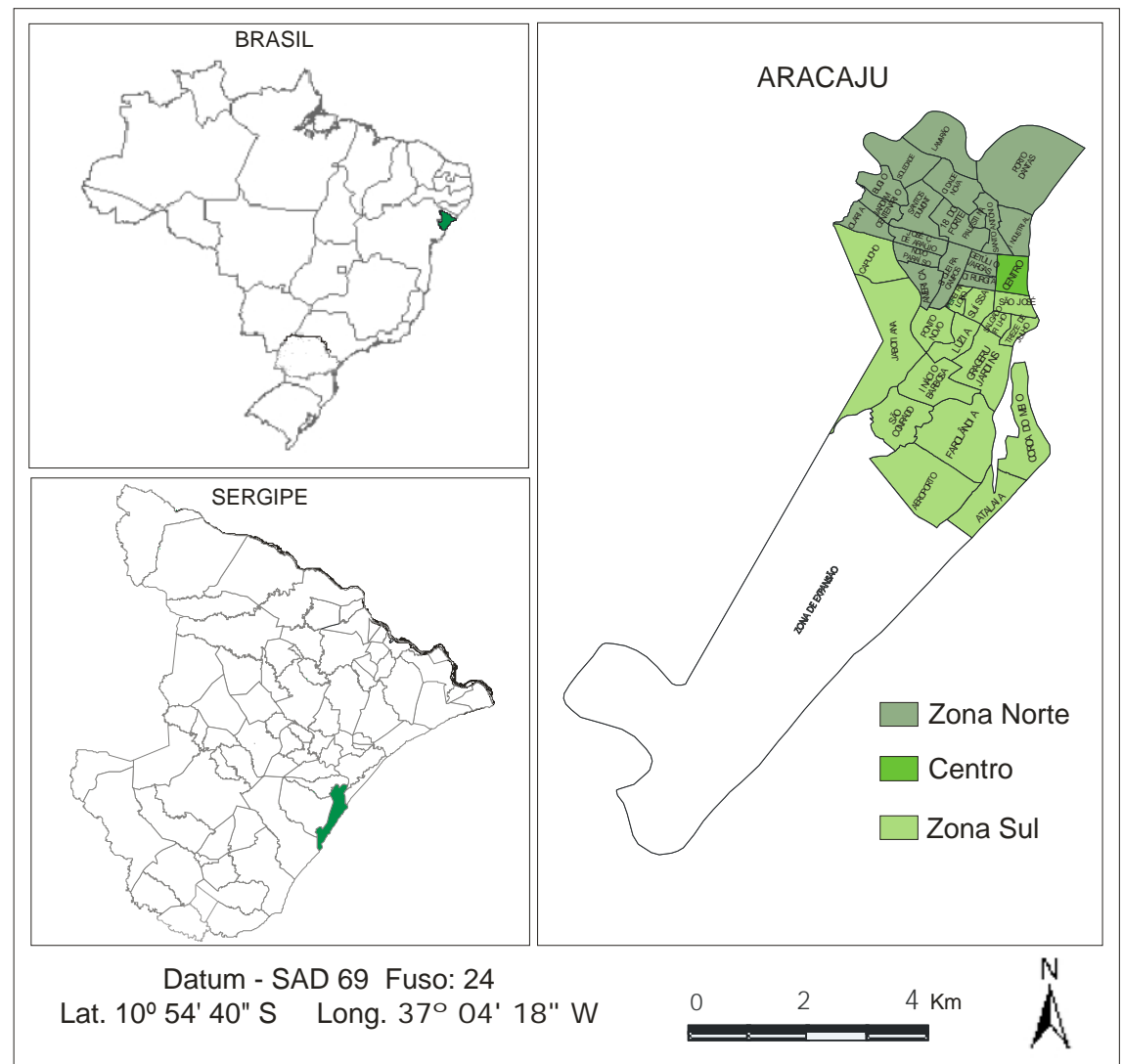

Figura 01 - Área de Estudo - Aracaju-SE.

\section{Procedimentos metodológicos}

A realização da pesquisa foi efetivada através de revisão bibliográfica e levantamento das árvores existentes nas áreas verdes públicas nos dezoito bairros da Zona Norte, quinze da zona sul e no Centro da capital, seguindo a segmentação estabelecida como critério para análise.

A metodologia consistiu num inventário de identificação e contabilização das espécies de estrato arbóreo e avaliação da cobertura vegetal das áreas verdes urbanas por meios de recursos técnicos e dos índices espaciais que foram anotados em planilhas, as quais continham os dados numéricos e as informações obtidas mediante observação in situ. Realizou-se a análise de dominância, concentração e diversidade das espécies encontradas na área de estudo, através da análise comparativa com outras cidades e estudos realizados.

As árvores com altura inferior a $2 \mathrm{~m}$ não foram recenseadas, pois causam sombreamento desprezível. A utilização do clinômetro digital foi fundamental para obtenção da altura e o dimensionamento da área de copa.

A determinação da área de copa das árvores foi efetuada através de procedimento visual com uso de trena de 50 metros, orientadas nas direções Norte-Sul e Leste-Oeste das copas sendo multiplicadas e gerando resultados em metros quadrado.

A pesquisa abordou a capacidade de sombreamento das áreas verdes públicas dos Bairros da Zona Norte, Centro e Zona Sul de Aracaju - SE, na perspectiva de melhoria da 
qualidade ambiental, baseando-se nos índices espaciais delineados por Simões et al. (2001) ao estudar a estrutura e condições da arborização urbana no bairro Vila Isabel do Rio de Janeiro. Os índices espaciais distinguidos são:

Índice de Sombreamento Arbóreo - ISA - É o percentual de área sombreada em relação à área total. O resultado obtido é o potencial de sombra resultante da soma das áreas de copa arbórea, que por sua vez é estimada por meio da projeção visual ao solo, aproximada pela composição de polígonos.

Índice de Densidade Arbórea - IDA - É o número de árvores existentes em cada 100m². Assim, o valor obtido denotará uma insuficiência ou abastamento da arborização na praça pública.

Os índices espaciais são definidos pelas seguintes fórmulas:

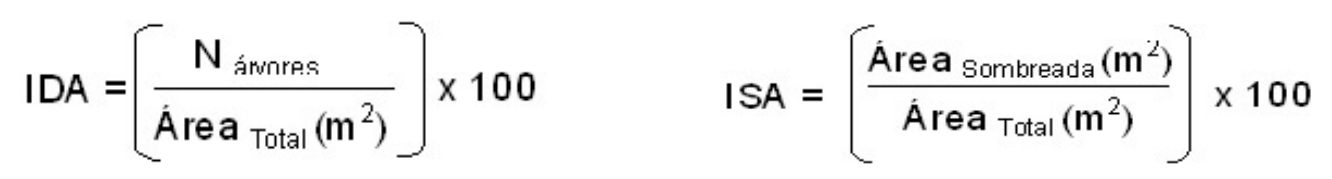

A partir dos resultados obtidos, os índices foram relacionados de acordo com Simões et al. (2001) que destaca que, para os bairros com predomínio de atividades comerciais, recomenda-se um ISA a partir de 30\%. Já para os bairros com função residencial, o valor recomendado é a partir de $50 \%$.

Ao Índice de Densidade Arbórea - IDA, confere a existência dos indivíduos arbóreos para cada $100 \mathrm{~m}^{2}$ de área da praça pública. Este procedimento denuncia a situação da área verde quando há carência ou abundância de vegetação arbórea, desse modo, torna-se importante adotá-lo na concepção de projetos de arborização urbana.

O estudo em questão trata da configuração da arborização existente na cidade e não leva em consideração a projeção da sombra de fachadas e telhados, que também contribuem para o conforto das cidades.

A representação cartográfica das áreas verdes públicas informou as situações e localização dos logradouros, a qual foi baseada na utilização das plantas baixas fornecidas pela EMURB - Empresa Municipal de Urbanização e do mapeamento digital produzido pela SEPLAN/PMA - Secretaria de Planejamento - Prefeitura Municipal de Aracaju (2003), referentes às praças. Em atividades de campo utilizou-se a câmara digital, recurso fundamental no registro fotográfico das áreas verdes urbanas.

\section{RESULTADOS E DISCUSSÃO}

\section{Composição e distribuição da arborização nas áreas verdes do centro de Aracaju-SE}

O Centro de Aracaju foi o local marcado inicialmente pelo planejamento chamado de "quadrado de Pirro", a partir deste bairro, a malha urbana se expandiu em todas as direções. 
Segundo IBGE (2000), a população corresponde a 8.146 habitantes, apresentando uma área de $13.635 \mathrm{Km}^{2}$, cuja densidade demográfica é de $6,1 \mathrm{hab} / \mathrm{Km}^{2}$.

No inventário das espécies mais utilizadas na arborização das áreas verdes públicas, verifica-se a presença de 23 espécies (Tabela 01), sendo incisiva a predominância do Pithecelobium glaziovvi (Mata-fome) e da Licania tomentosa (oiti), que juntas perfazem mais de $60 \%$.

Segundo Grey e Deneke apud Meneghetti (2003), é recomendável que a dominância da espécie arbórea seja entre $10 \%$ a 15\%, com intuito de garantir uma diversidade equilibrada. A justificativa seria a prevenção de riscos à longevidade da flora e fauna, combatendo o ataque de pragas e doenças. A este aspecto percebe-se a disparidade na concentração das espécies, pois, o $P$. glaziovvi junto a $L$. tomentosa as quais perfazem $62,16 \%$ das espécies das áreas verdes do Centro de Aracaju-SE.

O perigo de dominância de determinadas espécies podem proporcionar perda de considerável parte do patrimônio arbóreo, caso as espécies que compõe a arborização sejam susceptíveis ao ataque de pragas e doenças. Supondo que as espécies de $P$. Glaziovvi das praças do Centro da Cidade sejam atacadas por doenças letais tendo como concentração o valor que correspondem a 31,53\% (Tabela 01) das espécies desse bairro, então necessariamente será perdido este valor percentual do patrimônio arbóreo.

Tabela 01. Aspectos quantitativos das espécies nas áreas verdes públicas do Centro da Cidade de Aracaju - SE. 2006.

\begin{tabular}{cccc}
\hline NOME CIENTífICo & NOME VERNACULAR & $\begin{array}{c}\text { Frequência } \\
\text { Absoluta }\end{array}$ & $\begin{array}{c}\text { Frequência } \\
\text { Percentual (\%) }\end{array}$ \\
\hline Pithecelobium glaziovvi & Mata-fome & 140 & 31,53 \\
Licania tomentosa & Oiti & 136 & 30,63 \\
Tamarindus indica & Tamarindo & 46 & 10,36 \\
Clitoria fairchildiana & Sombreiro & 23 & 5,18 \\
Adenanthera pavonina & Tento-carolina & 15 & 3,37 \\
Terminalia cattapa & Amendoeira & 12 & 2,70 \\
Mangifera inica L. & Mangueira & 12 & 2,70 \\
Tapirira guianensis & Pau-pombo & 11 & 2,47 \\
Ficus microcarpa & Ficus & 10 & 2,25 \\
Bambusa oldhamii & Bambuzeiro & 9 & 2,03 \\
Pachira aquática & Castanheira-do-maranhão & 5 & 1,13 \\
Casuarina spp. & Casuarina & 4 & 0,90 \\
Prosopis juliflora & Algaroba & 4 & 0,90 \\
Espatodea ssp. & Espatódea & 4 & 0,90 \\
Delonix regia & Flamboyant & 3 & 0,67 \\
Ficus ssp. & Ficus & 2 & 0,45 \\
Anadenanthera colubrina & Angico & 2 & 0,45 \\
Outras espécies* & & 6 & 1,35 \\
\hline
\end{tabular}

Fonte - Dados da pesquisa de campo.

\footnotetext{
* Refere-se as espécies Caesalpinia echinata (pau-brasil), Eugenia malaccena (jambo), Eucalyptus ssp. (eucalipto), Psidium guajava (goiabeira), Cecropia sp. (umbaúba). Registrou-se apenas uma árvore de cada uma dessas espécies.
} 
A diversidade de espécies condiz com a proposta de Milano e Dalcin (2000) que admitem um mínimo de 7 a 10 e recomendam um número de 10 a 20 espécies para compor a arborização de uma cidade. No entanto, a problemática está na concentração de espécies, pois, para uma mesma espécie existe uma grande quantidade indivíduos numa mesma área, o que implica na não ocorrência de uma diversidade da arborização no ambiente urbano.

\section{Índices Espaciais do Bairro Centro, Aracaju-SE}

Com relação aos Índices Espaciais aferidos nas praças centrais apresentou melhores condições o parque Teófilo Dantas, ou seja, poderia ser proposto um modelo de arborização baseado neste logradouro quanto ao seu numero de espécies e arvores plantadas.

As praças da Bandeira, Fausto Cardoso e Camerino também apresentam resultados satisfatórios o entanto com relação ao quantitativo os índices encontrados refletem em locais que exercem funções de lazer,estética e ecológica.

A Praça da Bandeira apresentou um ISA de 51,38\% (Figura 02), que é uma porcentagem bastante aceitável, já que o índice recomendado é de 30\% para as áreas onde predominam o comércio e 50\% para as áreas onde temos o predomínio de residências, e considerando que a praça fica em uma área onde predominam os serviços temos então um índice convincente. Já com relação ao segundo índice calculado, o IDA, os resultados obtidos foram quase satisfatórios, sendo que a praça apresentou um índice próximo ao recomendado, sendo de 0,75 árvores para cada $100 \mathrm{~m}^{2}$ de praça (Figura 03), quando o índice ideal é que tenha pelo menos 1 árvore a cada $100 \mathrm{~m}^{2}$.

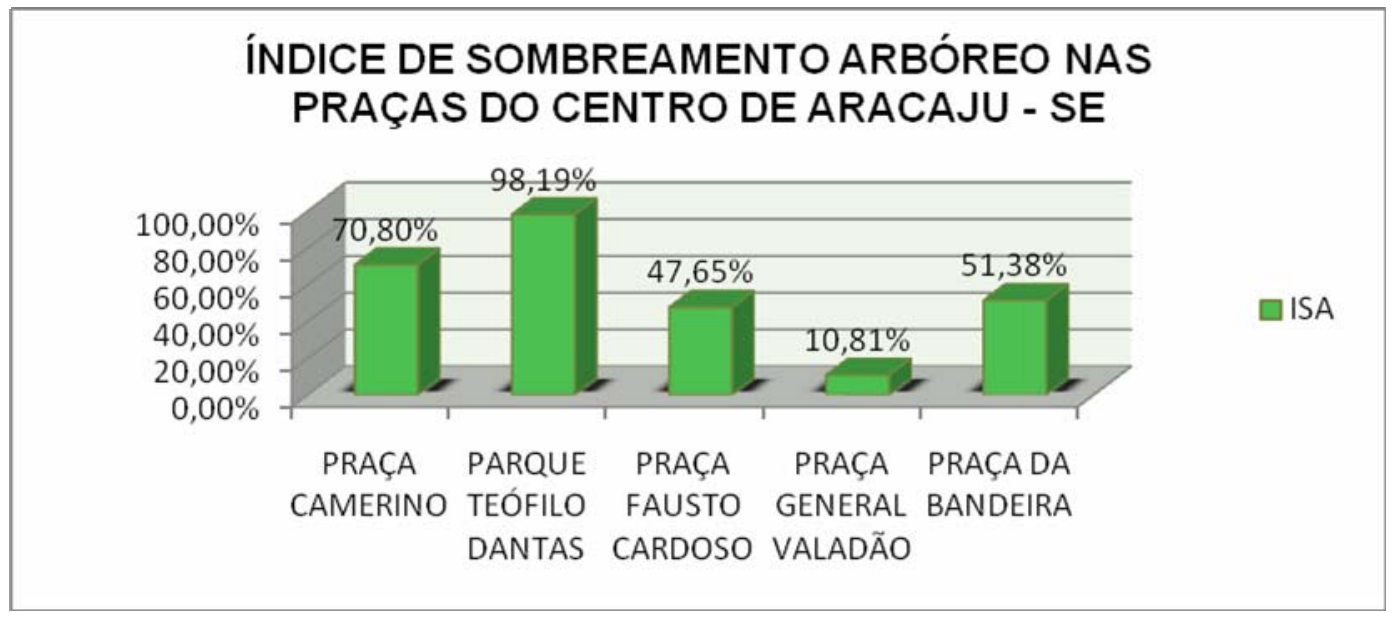

Figura 02. Análise do Índice de Sombreamento Arbóreo - ISA nas praças do Bairro Centro de Aracaju-SE. 2006.

Fonte - Dados da pesquisa de campo. 
$\mathrm{Na}$ Praça General Valadão foram encontrados índices bastante preocupantes. Esta praça apresenta uma quantidade muito reduzida de árvores para a área que abrange o que faz com que tenhamos um ISA e um IDA muito abaixo do ideal. O ISA foi de 10,81\% (Figura 02) e o IDA 0,16 árvores para cada $100 \mathrm{~m}^{2}$ de praça (Figura 03), que caracteriza um índice preocupante, levando-se em conta que é uma praça com numero de espécies e quantidade de arvores insuficientes para proporcionar conforto térmico.

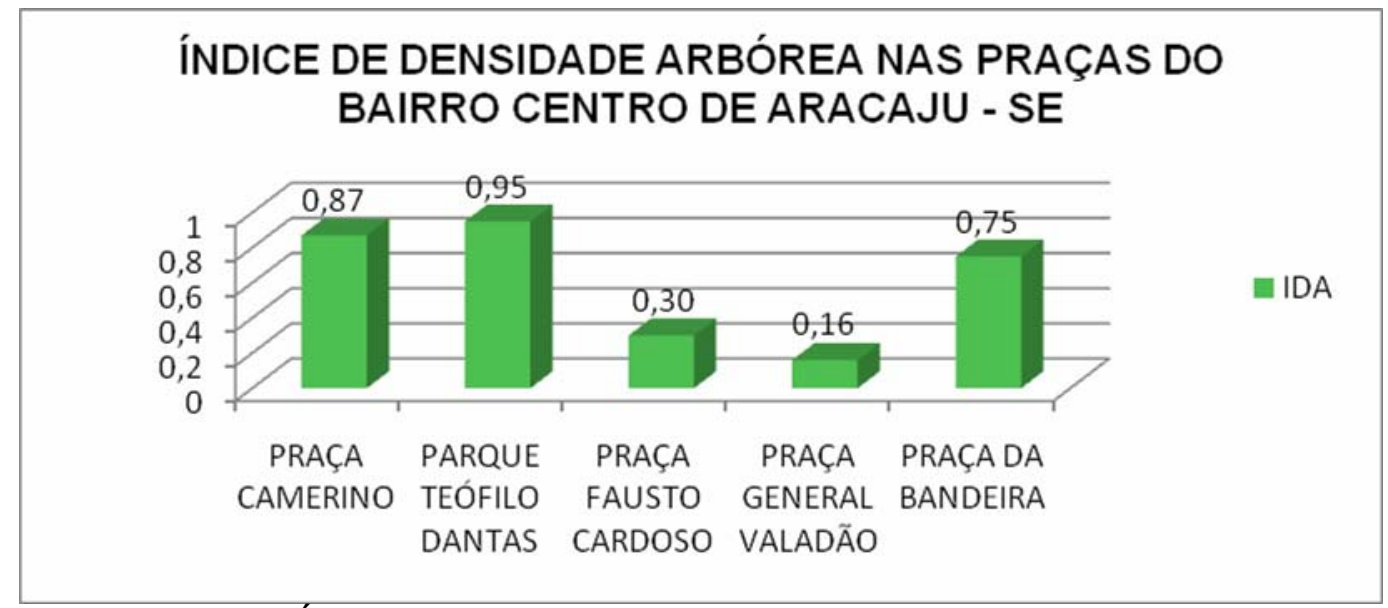

Figura 03. Análise do Índice de Densidade Arbórea - IDA nas praças do Bairro Centro de Aracaju-SE. 2006.

Fonte - Dados da pesquisa de campo.

Na Praça Camerino o ISA da praça perfaz 70,8\% (Figura 02), significando um resultado satisfatório já que se estabeleceu um índice adequado de 30\% para áreas onde predominam as atividades comerciais. O IDA é de 0,87 (Figura 03), constituindo um resultado próximo ao valor mínimo que é 1 individuo para cada $100 \mathrm{~m}^{2}$.

No Parque Teófilo Dantas com exceção do IDA, os resultados dos outros índices espaciais alcançaram um valor ideal. O ISA apresentado é de 98,19\% (Figura 02), constituindo um valor satisfatório, pois segundo Simões et al (2001) recomenda-se para os bairros onde predominam as atividades comerciais a obtenção do ISA acima de $30 \%$. O IDA registrado foi de 0,95 espécimes para cada $100 \mathrm{~m}^{2}$ (Figura 03), um resultado considerado ótimo quando comparado as demais praças da Zona Central de Aracaju - SE.

$\mathrm{Na}$ Praça Fausto Cardoso o IDA encontrado foi o segundo mais baixo, tendo como resultado o número de 0,30 árvores para cada $100 \mathrm{~m}^{2}$ de praça (Figura 03), o que fica muito abaixo do ideal. Quanto ao ISA a situação é melhor, obtendo-se o valor de 47,65\% de Índice de Sombreamento arbóreo, que é um valor que chega próximo ao ideal.

Dias (2002) aponta para a importância de indicadores que ajudem a evidenciar aos habitantes o grau de saúde de sua sociedade e os êxitos ou fracassos das políticas governamentais adotadas. O gerenciamento das áreas verdes urbanas necessita de diagnósticos quantitativos e qualitativos para o embasamento de políticas públicas. 


\section{Composição e distribuição da arborização nas áreas verdes da zona norte de Aracaju-}

\section{SE}

A Zona Norte abrange 18 bairros, onde reside cerca de $50 \%^{3}$ população de Aracaju, sendo que a maioria possui um menor poder aquisitivo, quando comparado com as melhores condições sócio-econômicas da população da maioria dos bairros da Zona Sul.

Os bairros desta região apresentam 24 praças públicas as quais foram objetos de estudo. Nesta porção da cidade os bairros Porto Dantas, Lamarão, Soledade, Palestina, Capucho, Olaria e Jardim Centenário, não são constituídos por áreas verdes públicas.

Verifica-se que o número de indivíduos arbóreos (442) e o número de espécies (17), 03 espécies: Pithecelobium glaziovvi, Clitoria fairchildiana e Terminalia cattapa totalizam $72,61 \%$ dos indivíduos da Zona Norte (Tabela 02).

Tabela 02. Aspectos quantitativos das espécies nas áreas verdes públicas da Zona Norte. Cidade de Aracaju - SE. 2006.

\begin{tabular}{cccc}
\hline NOME CIENTífICO & $\begin{array}{c}\text { NOME } \\
\text { VERNACULAR }\end{array}$ & $\begin{array}{c}\text { Frequência } \\
\text { Absoluta }\end{array}$ & $\begin{array}{c}\text { Frequência } \\
\text { Percentual (\%) }\end{array}$ \\
\hline Pithecelobium glaziovvi & Mata-fome & 188 & 42,53 \\
Clitoria fairchildiana & Sombreiro & 74 & 16,74 \\
Terminalia cattapa & Amendoeira & 58 & 13,34 \\
Ficus ssp. & Ficus & 34 & 7,91 \\
Syzigium janbolano & Jamelão & 15 & 3,39 \\
Licania tomentosa & Oiti & 12 & 2,71 \\
Ficus microcarpa & Ficus & 11 & 2,48 \\
Adenanthera pavonina & Tento-carolina & 9 & 2,03 \\
Delonix regia & Flamboyant & 7 & 1,58 \\
Tamarindus indica & Tamarindo & 6 & 1,35 \\
Cocus nucifera & Coqueiro & 6 & 1,35 \\
Leucaena leucocephala & Leucena & 6 & 1,35 \\
Azadirachta & Neem & 5 & 1,13 \\
Cecropia pachystachya & Umbaúba & 4 & 0,90 \\
Mangifera inica. & Mangueira & 3 & 0,67 \\
Genipa americana & Jenipapeiro & 2 & 0,45 \\
Pachira aquática & Castanheira-do-pará & 1 & 0,22 \\
Anacardium occidentale & Cajueiro & 1 & 0,22 \\
\hline
\end{tabular}

Fonte - Dados da pesquisa de campo.

A diversidade arbórea é condizente com o número recomendável - de 10 a 20 espécies - mas não há uma distribuição no que diz respeito ao número de indivíduos arbóreos para cada espécie.

\footnotetext{
${ }^{3}$ Segundo dados do IBGE (2000), encontra-se 234.195 habitantes na Zona Norte. Mas, como a população de Aracaju cresceu, provavelmente, este adensamento também deve ter aumentado. 
O P. glaziovvi (mata-fome) é a espécie de maior predominância, sendo bastante utilizada na arborização das áreas verdes, concentrando $42,53 \%$ das árvores existentes (Tabela 02).

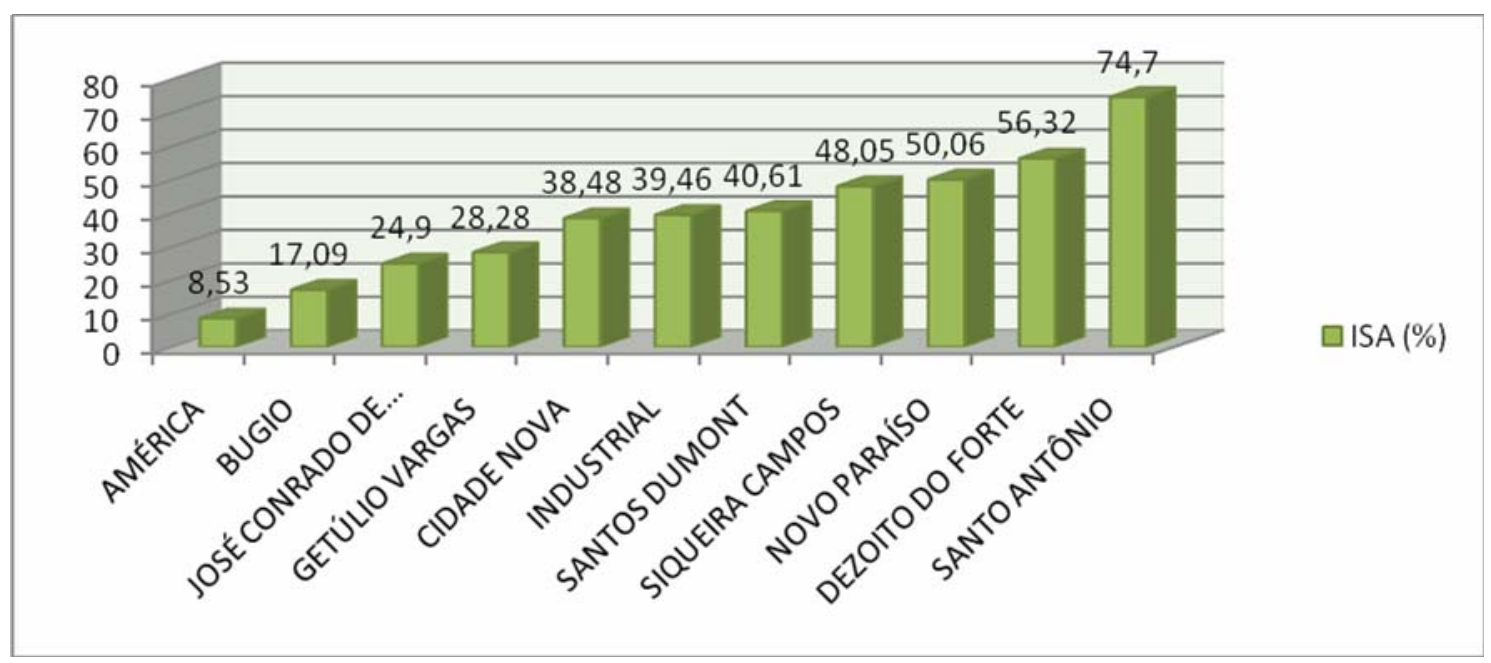

Figura 4. Índice de Sombreamento Arbóreo (ISA) bairros da Zona Norte de Aracaju - SE. Fonte - Dados da pesquisa de campo.

Com relação aos resultados do ISA (Figura 4), denota-se a distinta situação entre as Zonas Norte e Centro da capital, onde foi obtida a média de 39,58\% e 62,18\% respectivamente. Para os bairros com função predominantemente residencial, que é o caso da maioria dos logradouros da Zona Norte, recomenda-se uma ISA superior a $50 \%$ e no bairro onde predomina as atividades comerciais, a exemplo do Siqueira Campos, recomenda-se um ISA acima de 30\% (Simões et al, 2003).

O IDA revela a situação das áreas verdes urbanas no que diz respeito ao número de espécimes em relação à área $\left(\mathrm{m}^{2}\right)$ da praça. É importante ressaltar que o IDA está intimamente relacionado ao ISA, isto é, o número adequado de indivíduos arbóreos, para cada $100 \mathrm{~m}^{2}$, deve estar de acordo com a área de copa de cada árvore.

A densidade fitogeográfica nas áreas verdes públicas, nos bairros Santo Antônio, Cidade Nova e Novo Paraíso, observa-se os melhores resultados, obtendo respectivamente 0,82, 0,64, 0,57 árvores para cada $100 \mathrm{~m}^{2}$ (Tabela 04).

Tabela 04. Análise do Índice de Densidade Arbórea (IDA) dos bairros da Zona Norte de Aracaju - SE. 2006.

\begin{tabular}{lccc}
\hline \multicolumn{1}{c}{ BAIRROS DA ZONA NORTE } & $\begin{array}{c}\text { Frequência } \\
\text { Absoluta }\end{array}$ & $\begin{array}{c}\text { ÁREA DE } \\
\text { PRAÇAS (m²) }\end{array}$ & IDA \\
\hline Santo Antônio & 62 & 7520,39 & 0,82 \\
Cidade Nova & 3 & 465,19 & 0,64 \\
Novo Paraíso & 62 & 10815,8 & 0,57 \\
Siqueira Campos & 50 & 11980,1 & 0,42 \\
\hline
\end{tabular}




\begin{tabular}{lccc}
\hline Dezoito do Forte & 33 & 7985 & 0,41 \\
América & 16 & 4070,36 & 0,39 \\
Getúlio Vargas & 55 & 16874,3 & 0,33 \\
José Conrado de Araújo & 12 & 4145,91 & 0,29 \\
Bugio & 99 & 42337,7 & 0,23 \\
Industrial & 17 & 7335,98 & 0,23 \\
Santos Dumont & 29 & 13763 & 0,21 \\
\hline
\end{tabular}

Fonte - Dados da pesquisa de campo.

Não obstante, na maioria dos bairros constatou-se uma expressiva escassez de arborização, sobretudo, nos bairros Santos Dumont $(0,21)$, Bugio $(0,23)$ e Industrial $(0,23)$ (Tabela 04) uma vez que se denotou nestes os menores Índices de Densidade Arbórea da Zona Norte.

Composição e distribuição da arborização nas áreas verdes da Zona Sul de AracajuSE

A Zona Sul de Aracaju é formada por 14 bairros, sendo: Pereira Lobo, Suíssa, São Conrado, Salgado Filho Atalaia, Jabotiana, São José, 13 de Julho, Aeroporto, Luzia, Inácio Barbosa, Grageru, Farolândia e Ponto Novo, onde reside uma considerável parte da população de maior poder aquisitivo da capital sergipana.

Foram contabilizados 1865 indivíduos e levantadas 48 espécies diferentes, sendo que 27 delas se encontravam representadas por menos de 06 exemplares. As 21 espécies restantes, mais abundantes, foram responsáveis por $96,78 \%$ dos exemplares (Tabela 5).

Tabela 5. Freqüência Absoluta e Percentual do número de indivíduos por espécie com mais de 05 indivíduos da Zona Sul de Aracaju-SE. 2007.

\begin{tabular}{cccc}
\hline NOME CIENTífICO & $\begin{array}{c}\text { NOME } \\
\text { VERNACULAR }\end{array}$ & $\begin{array}{c}\text { Frequência } \\
\text { Absoluta }\end{array}$ & $\begin{array}{c}\text { Frequência } \\
\text { Percentual (\%) }\end{array}$ \\
\hline Terminalia cattapa & Amendoeira & 489 & 26,22 \\
Pithecellobium glaziovii & Mata-fome & 349 & 18,71 \\
Ficus spp. & Fícus & 224 & 12,01 \\
Clitoria fairchildiana & Sombreiro & 181 & 9,71 \\
Licania tomentosa & Oiti & 136 & 7,29 \\
Cocos nucifera & Coqueiro & 86 & 4,61 \\
Azadirachta indica & Neem & 72 & 3,86 \\
Mangifera indica. & Mangueira & 58 & 3,11 \\
Anacardium occidentale. & Cajueiro & 39 & 2,09 \\
Parkinsonia aculeata & Turco & 32 & 1,72 \\
\hline
\end{tabular}




\begin{tabular}{cccc}
\hline Delonix regia & Flamboyant & 25 & 1,34 \\
Syzygium jambolanum & Jamelão & 23 & 1,23 \\
Leucaena leucocephala & Leucena & 19 & 1,02 \\
Adenanthera pavonina & Tento carolina & 15 & 0,80 \\
Prosopis juliflora & Algaroba & 12 & 0,64 \\
Cassia fistula & Acácia & 9 & 0,48 \\
Pachira aquática & Castanheira & 8 & 0,43 \\
Cassia grandis & Cássia grande & 8 & 0,43 \\
Tamarindus indica & Tamarindo & 7 & 0,38 \\
Bauhinia forficata & Pata-de-vaca & 7 & 0,38 \\
Tabebuia serratifolia & Ipê-amarelo & 6 & 0,32 \\
\hline
\end{tabular}

Fonte - Dados da pesquisa de campo.

Para efeito de comparação, as 20 espécies mais abundantes representam 96,46\% da população, o que se assemelha bastante aos dados coletados por Meneghetti (2003) em ruas dos bairros da orla marítima do município de Santos-SP, uma vez que as 20 espécies perfaziam 91\% da população, além de Lima (1993), em bairros centrais de Piracicaba-SP, como também os resultados de Rachid e Couto (1999), para a cidade de São Carlos, nos quais 20 espécies representavam 90\% e $88 \%$ da população, respectivamente.

A distribuição da freqüência de espécies, apresentada na Tabela 5, ilustra a grande colaboração de três espécies: T. catappa com 26,22\%; P. glaziovii com 20\%; e Ficus spp. com 12,01\%; elas respondem, em conjunto, por 56,94\% dos indivíduos.

O recomendável, para arborização urbana, segundo Moll (1987), seria uma freqüência, por espécie, não superior a 10\%. Nesse sentido, o presente estudo apresenta três espécies com freqüências superiores ao recomendado. A medida para corrigir esse problema é diminuir o plantio das espécies de populações muito grandes e diversificar.

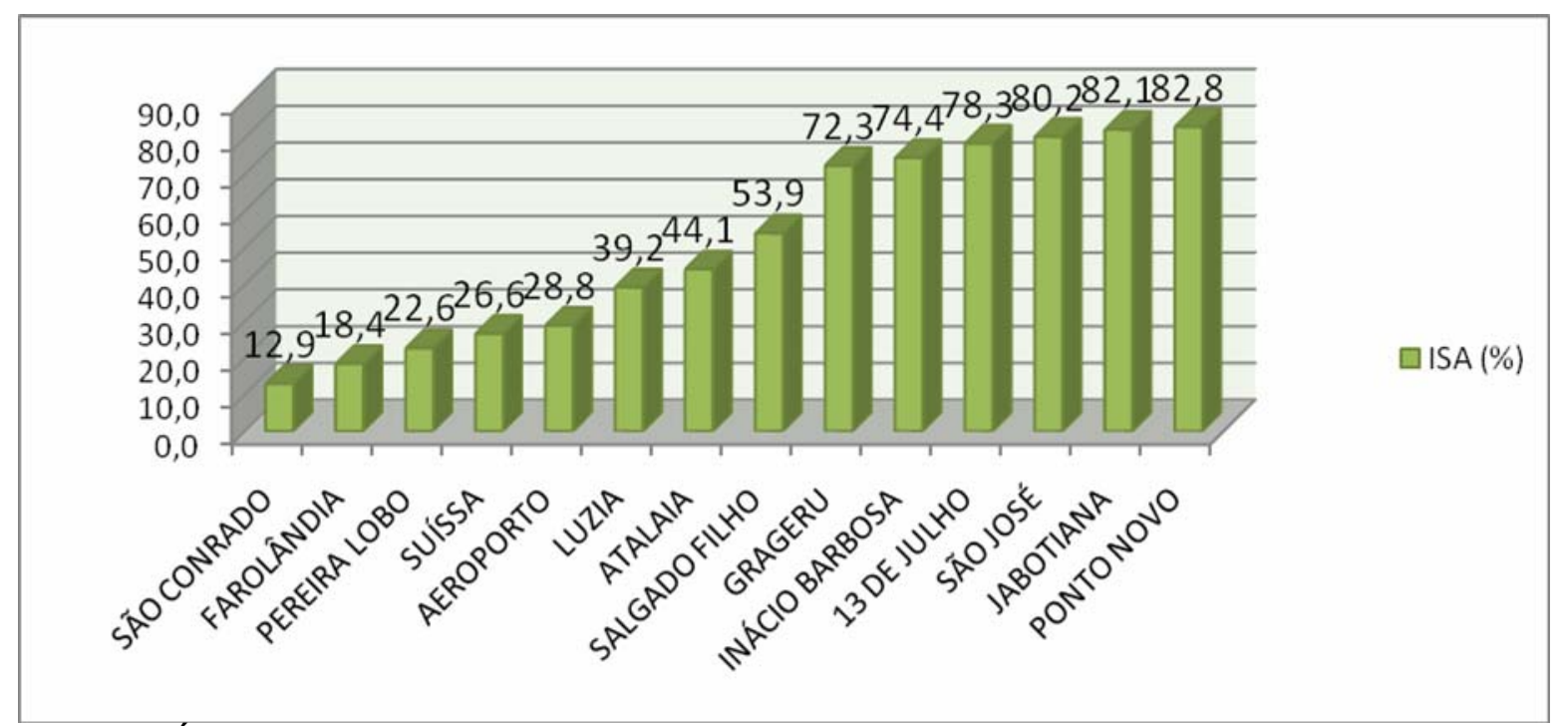

Figura 5. Índice de Sombreamento Arbóreo dos bairros da Zona Sul de Aracaju/SE. 2007. Fonte - Dados da pesquisa de campo. 
Com relação aos resultados do ISA, denota-se a situação na Zona Sul da capital, onde foi obtida a média de $47,77 \%$. Tendo em vista que os bairros apresentam função predominantemente residencial, recomenda-se uma ISA superior a $50 \%$ e nos bairros onde predominam as atividades comerciais, a exemplo do São José, uma vez que faz fronteira com o centro, recomenda-se um ISA acima de 30\% (Simões et al. 2003).

Os resultados obtidos dos índices de sombreamento arbóreo (ISA) dividiram em dois blocos os bairros da Zona Sul, 07 que atingiram os valores recomendados, sendo: Salgado Filho, Grageru, Inácio Barbosa, 13 de Julho, São José, Jabotiana, Ponto Novo. E sete dos bairros não atingiram os valores recomendados, são eles: São Conrado, Farolândia, Pereira Lobo, Suíssa, Aeroporto, Luzia, Atalaia (Figura 5).

Cabe ressaltar a ausência de área verde pública no bairro Coroa do Meio tornandose insuficiente para melhoria da qualidade ambiental e da paisagem cênica local, pois, evidenciam a necessidade de planejamento de espaços públicos que desempenhem os aspectos, ecológicos, estéticos e de lazer.

Tabela 6. Índice de Densidade Arbórea da arborização das áreas verdes públicas da Zona Sul de Aracaju-SE.

\begin{tabular}{cccc}
\hline BAIRROS DA ZONA SUL & $\begin{array}{c}\text { Frequência } \\
\text { Absoluta }\end{array}$ & $\begin{array}{c}\text { ÁREA DE PRAÇAS } \\
\left(\mathbf{m}^{\mathbf{2}}\right)\end{array}$ & IDA \\
\hline Farolândia & 232 & 111727,0 & 0,21 \\
Suíssa & 45 & 15934,90 & 0,28 \\
São Conrado & 34 & 11929,6 & 0,29 \\
Pereira Lobo & 17 & 4149,9 & 0,41 \\
Aeroporto & 129 & 24714,5 & 0,52 \\
Luzia & 200 & 33441,7 & 0,60 \\
Atalaia & 54 & 8093,13 & 0,67 \\
São José & 166 & 24610,1 & 0,67 \\
Salgado Filho & 48 & 6856,87 & 0,70 \\
Grageru & 120 & 15269,2 & 0,79 \\
13 de Julho & 119 & 11534,5 & 1,03 \\
Jabotiana & 141 & 13654,1 & 1,03 \\
Inácio Barbosa & 371 & 31822,9 & 1,17 \\
Ponto Novo & 189 & 15971,3 & 1,18 \\
\hline
\end{tabular}

Fonte - Dados da pesquisa de campo.

Os logradouros com maior Índice de Densidade Arbórea (IDA) são: Ponto Novo, Inácio Barbosa, Jabotiana e Treze de Julho, calcularam-se os melhores resultados, obtendo respectivamente 1,18, 1,17, 1,03 e 1,03 árvores para cada $100 \mathrm{~m}^{2}$ (Tabela 6). Nestes bairros 
observa-se a maior concentração de árvores em cada $100 \mathrm{~m}^{2}$ das praças, confirmando uma situação satisfatória de maior ocupação de árvores nas áreas verdes.

Nos bairros Farolândia, Suíssa e São Conrado constataram-se os respectivos IDA's, 0,21, 0,28 e 0,29 (Tabela 6). Estes índices são preocupantes e revelam a necessidade de implantação de indivíduos arbóreos para manutenção das áreas verdes públicas no tocante a presença de vegetação nestas áreas.

A maioria das áreas verdes públicas dos bairros da Zona Sul é marcada pela carência da vegetação arbórea, problema que compromete duas das funções básicas (ecológica e estética) que tais áreas devem exercer para melhorar a qualidade do ambiente urbano.

\section{CONCLUSÕES}

A ênfase dada às praças públicas se explica por estas estarem mais próximas do cotidiano da população em geral. Sem dúvida, medidas como a arborização e praças destinadas à área verde, podem contribuir na minimização do microclima urbano e, sobretudo, para a melhoria da qualidade ambiental e de vida humana.

De modo essencial faz-se necessário uma ação mais efetiva por parte do poder público no que se refere à arborização dos espaços públicos analisados na cidade. Cabe a população conhecer a importância da arborização urbana e exigir a criação de políticas específicas de planejamento criterioso e manutenção.

A freqüência das 05 espécies perfaz $74,75 \%$ dos indivíduos encontrados nas áreas verdes públicas de Aracaju, o que denota alta concentração a medida para corrigir esse problema é diminuir o plantio das espécies de populações muito grandes e diversificar.

A concentração das espécies na composição da arborização de praças, parques e ruas é o risco de doenças e pragas atacarem determinadas espécies menos resistentes levando a morte de significante parcela dos indivíduos que compõe a arborização.

A aplicação dos índices espaciais permitiu o diagnóstico espacial quantitativo das áreas verdes públicas nas Zonas Norte, Sul e Centro de Aracaju denotando a qualidade dos espaços públicos relacionados aos valores gerados pelos índices. Desse modo, foram obtidas as diferenciações quanto à capacidade de sombreamento arbóreo das áreas verdes por bairro (ISA), bem como foi registrado a ausência e escassez da vegetação de porte arbóreo nas praças, corroborado pelo IDA.

No Centro da cidade foram obtidos resultados para qualidade das áreas verdes bem aceitáveis em relação às condições da Zona Sul e principalmente a Zona Norte da capital. Neste caso é importante ressaltar que, o bairro Centro foi originado a partir de um planejamento urbano, durante a formação da capital aracajuana, diferentemente de muitos 
bairros, onde a ocupação e expansão, de modo geral, não foram acompanhadas de planejamento urbano.

Somente a partir destas informações, é que se poderá realizar um planejamento mais amplo, como implantação, manejo e conservação das áreas verdes melhorando a arborização existente, e principalmente, da que deverá ser implantada.

\section{REFERÊNCIAS BIBLIOGRÁFICAS}

ARAÚJO, H. M. de; VILAR, J. W. C.; WANDERLEY, L. de L; MELO e SOUZA, R. (Orgs.). O ambiente urbano, visões geográficas de Aracaju. São Cristóvão: Editora da UFS, 2006.

BATISTA, P. T. O meio ambiente, as cidades, as árvores urbanas e a SBAU. In: VI Congresso Nacional de Arborização Urbana. Anais... Goiânia, 2002.

BRASIL. IBGE - INSTITUTO BRASILEIRO DE GEOGRAFIA E ESTATÍSTICA, Disponível em: <http://www.ibge.hpg.gov.br>. Acesso em: 08 de maio. 2009.

CARVALHO, P. F. Repensando as áreas verdes urbanas. Território \& Cidadania. Ano III, número 2, 2003.

JESUS, T. S. de. Ambiente urbano, qualidade de vida e (in)sustentabilidade em cidades locais: Nossa Senhora da Glória/SE 2005, 122 f. Dissertação de mestrado (Mestrado em Meio Ambiente e Desenvolvimento). Universidade Federal de Sergipe, São Cristóvão, Sergipe, 2006.

LOMBARDO, M. A. Ilha de calor nas metrópoles: a exemplo de São Paulo. São Paulo: Hucitec, 1985.

MACEDO, S.S.; SAKATA, F.G. Parques urbanos no Brasil. São Paulo: Editora da Universidade de São Paulo, 2002. 208 p.

MENEGUETTI, G.I.P. Estudo de dois métodos de amostragem para inventário da arborização de ruas dos bairros da orla marítima do município de Santos-SP. Piracicaba, 2003. 100p. Dissertação (Mestrado) - Escola Superior de Agricultura "Luiz de Queiroz", Universidade de São Paulo. 2003.

MILANO, M.S.; DALCIN, E.C. Arborização de vias públicas. Rio de Janeiro, RJ: Light, 2000. 226p.

MOLL, G. Improving the health of the urban forest. American Forests, v.93, n.11/12, p.6164, Nov./Dec. 1987.

NUCCI, J.C.; CAVALHEIRO, F. Cobertura vegetal em áreas urbanas - conceito e método. GEOUSP, São Pulo: Departamento de Geografia/USP, 1999.

RACHID, C.; COUTO, H. T. Z. do. Estudo da eficiência de dois métodos de amostragem de árvores de rua na cidade de São Carlos - SP. Scientia Florestalis, n.56, p.59-68, dez. 1999.

SIMOES, L.O. de C., MAROTTA, H., PIRES, B.B.M., UMBELINO, L. F., COSTA, A.J.S.T. Índices de Arborização em espaço urbano: um estudo de caso no bairro de Vila Isabel, Rio de Janeiro, RJ. Anais do IX ENAU. Brasília, 2001. CD-Room. 